Although she was living with a common law husband, she never enjoyed sex with him, nor had she done so with her ex-husband. She always felt that sex was wrong and was so ashamed of her body that she never relaxed enough during lovemaking to enjoy it and she never experienced an orgasm.

As she presented with most of the diagnostic features of bulimia she was treated by a modified version ${ }^{4}$ of the outpatient treatment method originally described by Lacey in 1983.5 She responded very well to this treatment with an immediate drop in both the number of awakenings and binges in the first week (table). The size of the binges also dropped with a consistent shift

\begin{tabular}{lcc}
$\begin{array}{l}\text { Number of awakenings and binges during } 10 \text { weeks } \\
\text { Weeks of treatment }\end{array}$ & $\begin{array}{c}\text { No of nightly } \\
\text { awakenings per week }\end{array}$ & $\begin{array}{c}\text { No of binges } \\
\text { per week }\end{array}$ \\
\hline Before treatment & 22 & 20 \\
1 & 20 & 20 \\
2 & 5 & 5 \\
3 & 2 & 2 \\
4 & 2 & 2 \\
5 & 2 & 2 \\
6 & 3 & 3 \\
7 & 3 & 2 \\
8 & 4 & 3 \\
9 & 3 & 3 \\
10 & 3 & 3 \\
6 months after treatment & 1 & 1 \\
\hline
\end{tabular}

from huge to tiny. Three days after the start of treatment she reported her first night of unbroken sleep in months. The patient was followed up six months later and was found to be maintaining the same improved state, with further improvement in body image, self esteem, and confidence. She was less obsessed by food, less conscious of her body weight or shape, enjoying sex, and fully orgasmic. She was sleeping very well without drug medication and had stopped her nightly raids on the kitchen.

\section{Discussion}

Overeating and sleep disorders are closely connected as the hypothalamic centres for both eating and sleeping are adjacent. It is not surprising, therefore, that bulimia is often related to a sleep disorder, but an association with sleepwalking has not been described before. Interestingly the patient did not feel guilty after a binge, as most patients with bulimia do, possibly because she thought that the binges were out of her control as she was asleep and could not, therefore, be responsible for them.

In conclusion, patients who sleepwalk and indulge in binges in a state of semiconsciousness and then partially forget the incident may be suffering from a disguised form of bulimia. Awareness of such a possibility and detailed history taking, particularly of eating habits, could lead to the early diagnosis and treatment of some cases of bulimia that would otherwise go undetected.

\section{References}

1 Russell GFM. Bulimia nervosa: an ominous variant of anorexia nervosa. Psychol Med 1979;9: 429-48.

2 American Psychiatric Association. Diagnostic and statistical manual of mental disorders. 3rd ed. Washington, DC: American Psychiatric Association, 1980.

3 Fairburn CG, Cooper PJ. Self-induced vomiting and bulimia nervosa: an undetected problem. BrMed J 1982;284:1153-5.

Guirguis WR. Bulimia: the new epidemic. Postgraduate Doctor Middle East 1986;9:20-8.

$5 \mathrm{Lacey} \mathrm{JH}$. Bulimia nervosa, binge eating and psychogenic vomiting: a controlled treatment study and long term outcome. $\mathrm{BrMed}$ J 1983;286:1609-13.

(Accepted 25 June 1986)

\title{
Intermittent hypoxia in patients with unexplained polycythaemia
}

\author{
J C MOORE-GILLON, D F TREACHER, E J GAMINARA, T C PEARSON, I R CAMERON
}

\begin{abstract}
The aetiology of polycythaemia is unclear in up to $30 \%$ of patients. Twenty patients with unexplained polycythaemia were investigated to see whether they had an intermittent hypoxic stimulus to erythropoiesis that was undetected by conventional investigations for hypoxic secondary polycythaemia. Overnight polygraphic sleep studies showed that five patients had prolonged nocturnal hypoxaemia. Their arterial oxygen saturation was below $92 \%$, the level at which appreciable hypoxic stimulation of erythropoiesis occurs, for $26-68 \%$ of the time for which they were studied.
\end{abstract}

Considerable evidence is accumulating that intermittent hypoxia is a potent stimulus to erythropoiesis, and clinicians should consider the possibility of nocturnal hypoxia in patients with unexplained polycythaemia. Appropriate investigation will

\footnotetext{
Departments of Medicine and Haematology, United Medical and Dental Schools of Guy's and St Thomas's Hospitals, St Thomas's Hospital, London SE1 7EH

J C MOORE-GILLON, MA, MRCP, lecturer, department of medicine

D F TREACHER, MA, MRCP, research registrar, department of medicine

E J GAMINARA, MRCP, MRCPATH, senior registrar, department of haematology

T C PEARSON, MD, MRCPATH, reader, department of haematology

I R CAMERON, DM, FRCP, professor of medicine

Correspondence to: Dr J C Moore-Gillon, London Chest Hospital, London E2 9JS.
}

lead to the correct diagnosis of polycythaemia secondary to hypoxia in some cases previously regarded as idiopathic, and treatment may then be planned accordingly.

\section{Introduction}

Absolute polycythaemia may be due to a myeloproliferative disorder (primary proliferative polycythaemia) or secondary to chronic hypoxia, renal lesions, or one of several conditions occasionally associated with increased erythropoiesis. ${ }^{1}$ Initial investigations show the underlying cause in about $70 \%$ of patients; of the remaining $30 \%$ of patients, about one third will later show unequivocal primary proliferative polycythaemia ${ }^{2}$ or a previously undetected cause of secondary polycythaemia. This leaves a considerable proportion of patients with an increased red cell mass in whom the aetiology of the condition remains obscure.

Studies of red cell mass in patients with differing degrees of hypoxaemia suggest that there is little or no hypoxic stimulation of erythropoiesis until arterial oxygen saturation is less than $92 \%,{ }^{34}$ and saturations above this value are thus held by most clinicians to exclude hypoxic secondary polycythaemia. Measurements of arterial oxygen saturation are conventionally carried out when the patient is awake, but hypoxaemia during sleep is now well recognised ${ }^{56}$ and animal studies suggest that intermittent hypoxia is a potent stimulus to erythropoiesis. ${ }^{78}$ Furthermore, erythropoietin concentrations are increased in man after only a few hours of hypoxia.' These observations led us to propose that unexplained polycythaemia in 
some patients might be secondary to an intermittent nocturnal hypoxic stimulus to erythropoiesis that was undetected by conventional investigation.

\section{Patients and methods}

We studied 20 patients ( 19 men, one woman) with a mean age of $50 \cdot 3$ (range 23-68) years. Informed consent was obtained and the study approved by the hospital ethical committee. All patients had presented with absolute polycythaemia, packed cell volume $>0.51$, and red cell mass $>125 \%$ of the predicted value. ${ }^{10}$ None had any clinical or haematological evidence of primary proliferative polycythaemia. In each patient plasma urea and electrolyte concentrations, an intravenous urogram, haemoglobin affinity, and results of simple tests of respiratory function (spirometry and diffusing capacity for carbon monoxide) were normal. None was taking sedative or hypnotic drugs. Arterial oxygen saturation was measured by arterial puncture with the patients awake, supine, and breathing air. In all patients it was $>93 \%$ as determined spectrophotometrically with an Instrumentation Laboratories 282 CO-oximeter; this machine also measured carboxyhaemoglobin concentrations as a percentage of the total haemoglobin present. With the exception of one patient (case 2), all had undergone venesection and had a packed cell volume $<0.50$ at the time of study.

Overnight polygraphic studies of sleep, respiration, and oxygenation were carried out in each patient. Sleep was monitored by electroencephalography, electro-oculography, and electromyography; respiration was monitored by nose and mouth thermistors and chest wall impedance electrodes; and arterial oxygen saturation was recorded with an ear oximeter (Hewlett-Packard 47201A). All variables were recorded on a 16 channel SLE electroencephalography machine; arterial oxygen saturation was also plotted on an SE 3002 ultraviolet recorder, this trace being analysed manually to determine the minimum arterial oxygen saturation overnight and the time (minutes) for which the arterial oxygen saturation was $<92 \%$. The ear oximeter reading was also sampled every 30 seconds by a BBC microcomputer and stored on disk file. These data were used to calculate a simple arithmetic mean overnight saturation for each patient.

\section{Results}

Table I gives details of the patients studied. The mean body weight was $112 \%$ of ideal, with a range of $67-147 \%$. All patients had daytime arterial oxygen saturations $>93 \%$. Mean carboxyhaemoglobin concentration was $2 \cdot 8 \%$ (range $0 \cdot 2-5 \cdot 2 \%$ ). Mean red cell mass at the time of diagnosis of polycythaemia was $135 \%$ of the predicted value (range $125-167 \%$ ).

Table II shows the duration of the nocturnal study (total time for which saturation was recorded) and details of sleep and saturation during sleep. Of the 20 patients studied, five had prolonged nocturnal desaturation. For clarity they were taken as cases $1-5$ and are hereafter referred to as the hypoxic group. Cases 6-20 are referred to as the non-hypoxic group.

Table III compares the hypoxic and non-hypoxic groups. Tables II and III show that cases 1-5 represented a discrete group, in terms of their nocturnal saturation, rather than just one end of a continuum. Two patients (cases 1 and 2) had previously unrecognised obstructive sleep apnoea syndromes as

\section{TABLE I-Details of patients studied}

\begin{tabular}{|c|c|c|c|c|c|c|}
\hline $\begin{array}{l}\text { Case } \\
\text { No }\end{array}$ & $\begin{array}{c}\text { Age } \\
\text { (years) }\end{array}$ & Sex & $\begin{array}{l}\text { Weight } \\
\text { (\% ideal) }\end{array}$ & $\begin{array}{l}\text { Red cell mass } \\
\text { (\% predicted) }\end{array}$ & $\begin{array}{l}\text { Arterial oxygen } \\
\text { saturation } \star(\%)\end{array}$ & $\begin{array}{l}\text { Carboxyhaemo- } \\
\text { globin }(\%)^{\star}\end{array}$ \\
\hline 1 & 66 & $\mathbf{M}$ & 145 & 125 & $95 \cdot 2$ & $1 \cdot 3$ \\
\hline 2 & 45 & M & 147 & 146 & $94 \cdot 0$ & $5 \cdot 2$ \\
\hline 3 & 59 & $M$ & 107 & 128 & 93.8 & $5 \cdot 3$ \\
\hline 4 & 41 & $M$ & 105 & 167 & 93.5 & 4.6 \\
\hline 5 & 58 & $M$ & 91 & 125 & 94.5 & $2 \cdot 9$ \\
\hline 6 & 60 & $M$ & 109 & 128 & 94.9 & 1.8 \\
\hline 7 & 30 & $M$ & 83 & 139 & $97 \cdot 1$ & 1.6 \\
\hline 8 & 52 & M & 95 & 153 & $95 \cdot 7$ & $2 \cdot 1$ \\
\hline 9 & 23 & $M$ & 127 & 161 & $93 \cdot 1$ & $4 \cdot 3$ \\
\hline 10 & 30 & $M$ & 126 & 135 & $94 \cdot 1$ & $5 \cdot 1$ \\
\hline 11 & 56 & $M$ & 117 & 132 & 94.5 & 0.2 \\
\hline 12 & 41 & $M$ & 67 & 133 & $97 \cdot 9$ & $2 \cdot 0$ \\
\hline 13 & 62 & $M$ & 132 & 134 & 94.0 & 0.6 \\
\hline 14 & 57 & $M$ & 90 & 125 & 95.5 & 3.9 \\
\hline 15 & 51 & $\mathbf{M}$ & 133 & 139 & $95 \cdot 2$ & $2 \cdot 3$ \\
\hline 16 & 62 & $\mathbf{M}$ & 111 & 125 & 95.0 & $2 \cdot 6$ \\
\hline 17 & 61 & $M$ & 98 & 132 & $95 \cdot 1$ & $2 \cdot 7$ \\
\hline 18 & 68 & $M$ & 143 & 126 & $94 \cdot 2$ & $3 \cdot 1$ \\
\hline 19 & 45 & $M$ & 95 & 126 & $94 \cdot 8$ & $2 \cdot 3$ \\
\hline 20 & 52 & $\mathrm{~F}$ & 118 & 126 & $94 \cdot 4$ & $2 \cdot 1$ \\
\hline
\end{tabular}

^Determined spectrophotometrically with patient awake.
TABLE II-Results of overnight studies and arterial oxygen saturations

\begin{tabular}{|c|c|c|c|c|c|c|c|c|}
\hline \multirow{2}{*}{$\begin{array}{l}\text { Case } \\
\text { No }\end{array}$} & \multirow{2}{*}{$\begin{array}{c}\text { Duration } \\
\text { of study } \\
\text { (min) }\end{array}$} & \multicolumn{2}{|c|}{ Time (min) spent: } & \multirow{2}{*}{$\begin{array}{l}\text { REM sleep } \\
-\quad \text { as } \% \text { of } \\
\text { total sleep }\end{array}$} & \multicolumn{3}{|c|}{$\begin{array}{l}\text { Arterial oxygen } \\
\text { saturation }^{\star}(\%)\end{array}$} & \multirow{2}{*}{$\begin{array}{c}\text { Time for } \\
\text { which } \\
\text { oxygen } \\
\text { - saturation } \\
<92 \% \text { (min }\end{array}$} \\
\hline & & Awake & Asleep & & Maximum & Minimum & Mean & \\
\hline l & 348 & 42 & 306 & 23 & 98 & 77 & $91 \cdot 9$ & 89 \\
\hline 2 & 336 & 11 & 325 & 17 & 97 & 60 & $87 \cdot 1$ & 187 \\
\hline 3 & 321 & 62 & 259 & 22 & 98 & 64 & 89.6 & 219 \\
\hline 4 & 310 & 45 & 265 & 20 & 98 & 80 & $91 \cdot 0$ & 82 \\
\hline 5 & 295 & 46 & 249 & 12 & 95 & 83 & $90 \cdot 8$ & 192 \\
\hline 6 & 365 & 52 & 313 & 25 & 98 & 87 & 93.9 & 1 \\
\hline 7 & 475 & 22 & 453 & 22 & 99 & 89 & $95 \cdot 6$ & 1 \\
\hline 8 & 315 & 65 & 250 & 10 & 99 & 88 & 94.8 & 0 \\
\hline 9 & 325 & 33 & 292 & 21 & 99 & 89 & $95 \cdot 8$ & 1 \\
\hline 10 & 382 & 41 & 341 & 22 & 99 & 90 & $96 \cdot 3$ & 0 \\
\hline 11 & 320 & 29 & 291 & 18 & 96 & 88 & $92 \cdot 3$ & 0 \\
\hline 12 & 249 & 38 & 211 & 21 & 99 & 94 & 96.7 & 0 \\
\hline 13 & 322 & 29 & 303 & 21 & 98 & 87 & $94 \cdot 7$ & 1 \\
\hline 14 & 353 & 30 & 323 & 16 & 98 & 93 & 95.6 & 0 \\
\hline 15 & 376 & 71 & 305 & 13 & 99 & 88 & 94.6 & 1 \\
\hline 16 & 345 & 32 & 313 & 16 & 99 & 90 & 96.6 & 0 \\
\hline 17 & 454 & 22 & 432 & 18 & 98 & 92 & $95 \cdot 1$ & 0 \\
\hline 18 & 365 & $35 t$ & $330+$ & & 99 & 85 & 93.6 & 1 \\
\hline 19 & 380 & $91^{\circ}$ & $289^{\circ}$ & 16 & 99 & 92 & $94 \cdot 6$ & 8 \\
\hline 20 & 490 & $45 \dagger$ & $445 \dagger$ & & 99 & 91 & $95 \cdot 1$ & 0 \\
\hline
\end{tabular}

REM=Rapid eye movement.

†Electroencephalogram technically unsatisfactory: value determined by clinical observation.

TABLE III-Comparison of hypoxic and non-hypoxic groups. Values are means (ranges)

\begin{tabular}{|c|c|c|}
\hline & Hypoxic group & Non-hypoxic group \\
\hline Daytime oxygen tension $(\mathrm{kPa})$ & $10 \cdot 9(10 \cdot 3-11 \cdot 5)$ & $11 \cdot 2(9 \cdot 9-13 \cdot 1)$ \\
\hline Daytime carbon dioxide tension $(\mathrm{kPa})$ & $4 \cdot 9(4 \cdot 5 \cdot 6 \cdot 1)$ & $4 \cdot 9(4 \cdot 3-5 \cdot 7)$ \\
\hline Daytime oxygen saturation $(\%)^{\star}$ & $94 \cdot 2(93 \cdot 6-95 \cdot 2)$ & $95 \cdot 2(93 \cdot 1-97 \cdot 9)$ \\
\hline Carboxyhaemoglobin (\%) & $3 \cdot 9(1 \cdot 3-5 \cdot 3)$ & $2 \cdot 4(0 \cdot 2-5 \cdot 1)$ \\
\hline Oxygen saturation at night $(\%) \dagger$ & $90 \cdot 1(87 \cdot 1-91 \cdot 9)$ & $95 \cdot 4(93 \cdot 6-96 \cdot 7)$ \\
\hline Minimum oxygen saturation at night $(\%) \dagger$ & $73 \cdot 2(60-83)$ & $91 \cdot 0(85-94)$ \\
\hline Time for which oxygen saturation $<92 \%$ (min) & $154(82-219)$ & $1 \quad(0-8)$ \\
\hline
\end{tabular}

*Determined spectrophotometrically.

tDetermined with oximeter.

Conversion: SI to traditional units-Blood gas tensions: $1 \mathrm{kPa} \approx 7.5 \mathrm{~mm} \mathrm{Hg}$.

defined by Guilleminault et al..$^{5}$ These patients had a mean of 64 and 31 episodes of apnoea/hour, respectively.

One patient (case 1) had no sleeping partner and no complaints of snoring; he had occasional daytime somnolence. The other (case 2) had no history of snoring or daytime somnolence. Even after retrospective review of cases 1 and 2 we did not think that the diagnosis of obstructive sleep apnoea syndrome was clear from the history and clinical presentation. In cases 3-5 the prolonged desaturation observed was due to periods of hypoventilation without apnoeas.

The number of hypoxaemic episodes, defined as a fall in arterial oxygen saturation of at least $4 \%$ from the preceding stable value during sleep, was determined in each patient. In the hypoxic group the mean number of hypoxaemic episodes was 210 (range 58-361), compared with 3.8 (range $0-15$ ) in the non-hypoxic group. There was a dramatic difference between the two groups in the length of time for which their nocturnal saturation was below $92 \%$ (table III).

The hypoxic group was between $91 \%$ and $147 \%$ of their ideal body weight (mean 119\%). The non-hypoxic group was $67-143 \%$ of their ideal (mean $110 \%$ ). Mean red cell mass at the time of diagnosis of polycythaemia was $138 \%$ of the predicted value (range $125-167 \%$ ) in the hypoxic group and $134 \%$ of the predicted value (range $125-161 \%$ ) in the non-hypoxic group. Symptoms of snoring and daytime somnolence were as prevalent in the nonhypoxic group as in the hypoxic group.

\section{Discussion}

We studied 20 patients in whom the possibility of their polycythaemia being secondary to hypoxia had previously been discounted because their daytime arterial oxygen saturation was considerably above $92 \%$, the value below which hypoxic stimulation of erythropoiesis is generally regarded as occurring. ${ }^{34}$ Five of the patients had prolonged nocturnal hypoxaemia, with saturation below $92 \%$ for lengthy periods. Brief respiratory irregularities and 
minor desaturation occur during sleep in some apparently normal subjects. ${ }^{11}$ In studies of older patients such features have been more pronounced, but, although the degree of desaturation approached that seen in our hypoxic group, the episodes recorded were still fairly brief. ${ }^{12}$ The duration of nocturnal hypoxia recorded was therefore much less in these normal subjects than that in our five patients with unexplained polycythaemia. Similarly, the number of hypoxaemic episodes in our patients was much greater than that observed in a study of normal subjects by Catterall et al. ${ }^{13}$

In animals intermittent hypoxia of similar duration to that seen in our patients will, when repeated daily, produce sustained polycythaemia $^{78}$; in man a single acute hypoxic exposure of six hours' duration produces measurable increases in erythropoietin. ${ }^{9}$ We believe that our observations provide strong evidence for the hypothesis that intermittent nocturnal hypoxia may lead to polycythaemia. Some patients with apparently unexplained polycythaemia actually have hypoxic secondary polycythaemia. Similarly, the finding that sustained polycythaemia can result from intermittent nocturnal hypoxia without daytime hypoxia may lend support to the suggestion that differing degrees of nocturnal hypoxaemia are responsible for the differing degrees of polycythaemia seen in hypoxic patients with apparently similar daytime saturations. ${ }^{314}$ is As the patients we studied were not randomly selected we cannot suggest a figure for the prevalence of nocturnal hypoxia among patients with unexplained polycythaemia. The appreciable proportion of our patients with nocturnal hypoxia suggests that it may be a fairly common condition.

Polycythaemia may of itself lead to hypoxaemia. ${ }^{16}$ Although this may not be of sufficient degree to stimulate erythropoiesis, daytime hypoxaemia predisposes to more profound desaturation at night ${ }^{17}$ and this might be severe enough to lead to increased erythropoiesis. Patients with polycythaemia from causes other than hypoxia might thus eventually develop a component of hypoxic secondary polycythaemia, and studies of nocturnal oxygenation in untreated patients with polycythaemia might be criticised on the grounds of possible confusion between cause and effect. Our study of patients after venesection avoids this criticism, being intended to establish whether polycythaemia may result from nocturnal hypoxia rather than cause it, but in so doing it may well have underestimated the role of nocturnal hypoxia in initiating and perpetuating polycythaemia.

Other factors may compound the problem of recognising covert hypoxaemia in patients with unexplained polycythaemia. The role of smoking may be particularly relevant. Carbon monoxide produced by smoking binds with haemoglobin, the resulting carboxyhaemoglobin being unavailable for the carriage of oxygen ${ }^{18}$ Carbon monoxide also induces changes in the affinity of the remaining haem sites for oxygen, and this further reduces delivery of oxygen to the tissues. ${ }^{19}$ Smoking alone, without lung disease, may by these means occasionally result in polycythaemia, ${ }^{20}$ and Calverley $e t$ al showed a correlation of 0.73 between carboxyhaemoglobin concentration and red cell mass in a series of patients with polycythaemia secondary to hypoxaemic chronic obstructive airways disease..$^{21}$ The percentage of carboxyhaemoglobin present in patients with polycythaemia who smoke will not be shown by the calculated saturation figures produced by conventional blood gas machines, and daytime desaturation may thus effectively be masked. It was for this reason that we used spectrophotometric determinations of saturation and considered only patients whose daytime saturations were still above 92\% even when the carboxyhaemoglobin concentration was taken into account in the calculation. Nevertheless, 14 of our patients admitted to being current smokers; the values for nocturnal saturation as recorded by ear oximetry in these patients will include residual carboxyhaemoglobin as well as oxyhaemoglobin, leading to an underestimate of the true hypoxic stimulus to erythropoiesis at night. Smoking may be an important factor in many patients with polycythaemia, and we emphasise that determination of carboxyhaemoglobin concentrations is an important part of the investigation of all such patients.

An additional matter that should be considered is that we encouraged our patients to drink their normal quantities of alcohol before sleep but believe that few actually did so. This factor, along with the unfamiliarity of the sleep laboratory and equipment, might have led to the measurements of respiration and oxygenation obtained during the study being unrepresentative of what would have occurred during a normal night at home in some cases. Some patients spent a considerable part of the study period awake, and in some rapid eye movement sleep as a proportion of total sleep was below the normal $20-25 \% .{ }^{22}$ These factors and the complicating issue of carboxyhaemoglobin, discussed above, mean that we may have underestimated the degree of nocturnal hypoxaemia in our five "positive" patients and also obtained false negative results in some of those we regarded as non-hypoxic at night. Finally, the hypoxic stimulus to erythropoiesis produced by desaturation is unlikely to be accurately represented by the simple arithmetic mean of values of arterial oxygen saturation. ${ }^{23}$

We suggest that in some patients with unexplained polycythaemia the mechanism responsible is intermittent nocturnal hypoxaemia and that clinicians dealing with such patients should be aware of this possibility. Appropriate investigation will enable the correct diagnosis of hypoxic secondary polycythaemia to be established and treatment planned accordingly.

We are indebted to Dr Peter Fenwick, consultant clinical neurophysiologist, St Thomas's Hospital, for his invaluable advice and help with the electroencephalograms. This study was supported by the research (endowments) committee of St Thomas's Hospital.

\section{References}

1 Wetherley-Mein G, Pearson TC. The myeloproliferative disorders: the polycythaemias. In: Hardisty RM, Weatherall DJ, eds. Blood and its disorders. 2nd ed. Oxford: Blackwell Scientific, 1982:1268-89.

2 Pearson TC, Wetherley-Mein G. The course and complications of idiopathic erythrocytosis. Clin Lab Haematol 1979;1:189-96.

3 Balcerzak SP, Bromberg PA. Secondary polycythaemia. Semin Haematol 1975;12:353-82.

4 Stradling JR, Lane DJ. Development of secondary polycythaemia in chronic airways obstruction. Thorax 1981;36:321-5.

5 Guilleminault C, Tilkian A, Dement WC. The sleep apnea syndromes. Annu Rev Med 1976;27:465-84.

6 Douglas NJ, Leggett RJE, Calverley PMA, Brash HM, Flenley DC, Brezinova V. Transient hypoxaemia during sleep in chronic bronchitis and emphysema. Lancet 1979;i:1-4.

Moore-Gillon JC, Cameron IR. Right ventricular hypertrophy and polycythaemia in rats after intermittent exposure to hypoxia. Clin Sci 1985;69:595-9.

8 Nattie EE, Doble EA. Threshold for intermittent hypoxia-induced right ventricular hypertrophy in the rat. Respir Physiol 1984;56:253-9.

9 Faura J, Ramos J, Reynafarje C, English E, Finne P, Finch CA. Effect of altitude on erythropoiesis. Blood 1969;33:668-76.

10 Nadler SB, Hidlago JU, Block T. Prediction of blood volume in normal human adults. Surgery 1962;51:224-32.

11 Block AJ, Boysen PG, Wynne JW, Hunt LA. Sleep apnea, hypopnea and oxygen desaturation in normal subjects: a strong male predominance. N Engl f Med 1979;300:513-7.

12 Bixler EO, Kales A, Cadieux RJ, Vela-Bueno A, Jacoby JA, Soldatos CR. Sleep apneic activity in Bixler EO, Kales A, Cadieux RJ, Vela-Bueno A, Jacoby JA,
older healthy subjects. $\mathcal{F}$ Appl Physiol 1985;58:1597-601.

13 Catterall JR, Calverley PMA, Shapiro CM, Flenley DC, Douglas NJ. Breathing and oxygenation during sleep are similar in normal men and normal women. Am Rev Respir Dis 1985;132:86-8. 4 Flenley DC. Hypoxaemia during sleep. Thorax 1980;35:81-4.

15 Wedzicha JA, Cotes PM, Empey DW, Newland AC, Royston JP, Tam RC. Serum immunoreactive erythropoietin in hypoxic lung disease with and without polycythaemia. Clin Sci 1985;69:413-22.

16 Murray JF. Arterial studies in primary and secondary polycythemic disorders. Am Rev Respir Dis 1965;92:435-49.

17 Stradling JR, Lane DJ. Nocturnal hypoxaemia in chronic obstructive pulmonary disease. Clin $\mathrm{S}$ 1983;64:213-22.

18 Brody JS, Coburn RF. Carbon-monoxide induced arterial hypoxaemia. Science 1969;164:1297-8. 19 Collier CR. Oxygen affinity of human blood in the presence of carbon monoxide. $\mathcal{F}$ Appl Physiol 1976;40:487-90.

20 Sagone AL, Balcerzak SP. Smoking as a cause of erythrocytosis. Ann Intern Med 1975;82:512-5.

20 Sagone AL, Balcerzak SP. Smoking as a cause of erythrocytosis. Ann Intern Med 1975;82:512-5. polycythemia in hypoxic cor pulmonale. Am Rev Respir Dis 1982;125:507-10.

22 Walton J. Consciousness and unconsciousness. In: Walton J, ed. Brain's diseases of the nervous Walton J. Consciousness and unconsciousness. In: Walton J, ed.
system. 9th ed. Oxford: Oxford University Press, 1985:640-4.

23 Meanock CI, Guyatt AR, Cumming G. The assessment of nocturnal oxygen saturation. Clin Sci 1983;64:507-13.

(Accepted I fuly 1986) 